\title{
Electron Detachment Dissociation of Neutral and Sialylated Oligosaccharides
}

\author{
Julie T. Adamson and Kristina Håkansson \\ Department of Chemistry, University of Michigan, Ann Arbor, Michigan, USA
}

\begin{abstract}
Electron detachment dissociation (EDD) has recently been shown by Amster and coworkers to constitute a valuable analytical approach for structural characterization of glycosaminoglycans. Here, we extend the application of EDD to neutral and sialylated oligosaccharides. Both branched and linear structures are examined, to determine whether branching has an effect on EDD fragmentation behavior. EDD spectra are compared to collisional activated dissociation (CAD) and infrared multiphoton dissociation (IRMPD) spectra of the doubly and singly deprotonated species. Our results demonstrate that EDD of both neutral and sialylated oligosaccharides provides structural information that is complementary to that obtained from both CAD and IRMPD. In all cases, EDD resulted in additional cross-ring cleavages. In most cases, cross-ring fragmentation obtained by EDD is more extensive than that obtained from IRMPD or CAD. Our results also indicate that branching does not affect EDD fragmentation, contrary to what has been observed for electron capture dissociation (ECD). (J Am Soc Mass Spectrom 2007, 18, 2162-2172) (c 2007 American Society for Mass Spectrometry
\end{abstract}

G lycosylation is a highly prevalent posttranslational modification (PTM), whose role has been linked to a wide variety of biological activities [1, 2], ranging from protein folding [3] to immune system response [4]. Unlike most biomolecules, oligosaccharides often exist as several isomeric forms with diverse linkages, and may form linear or branched structures. Complete structural characterization of oligosaccharides requires the determination of constituent monosaccharides, their linkage, sequence, and branching patterns. Given their diversity and structural complexity, structural elucidation of oligosaccharides often relies upon a wide range of analytical methodologies, of which nuclear magnetic resonance spectroscopy and mass spectrometry are two vital techniques. Tandem mass spectrometry (MS/MS) is widely used for glycan structural characterization [5-7], due to the advent of instruments that provide high-quality spectra from even low-abundance molecular species.

Tandem mass spectra of oligosaccharides consist mainly of glycosidic and cross-ring product ions. Glycosidic cleavage occurs between monosaccharide units and provides information regarding saccharide sequence and branching. Cross-ring cleavages can provide valuable information regarding saccharide linkage, particularly when occurring at branching residues. Several factors are known to affect oligosaccharide fragmentation and the degree of cross-ring fragmentation, such as the ionizing cation, the lifetime of the ion before detection, and the energy deposited into the ion.

Address reprint requests to Dr. Kristina Håkansson, University of Michigan, Department of Chemistry, 930 N. University, Ann Arbor, MI 481091055, USA. E-mail: kicki@umich.edu
Typically, neutral oligosaccharides are analyzed in positive-ion mode, by their protonated forms or through metal ion adduction. In addition, chemical derivatization such as permethylation is widely used to increase sensitivity, reduce molecular ion lability, and produce structurally diagnostic product ions [8-10]. Low-energy activation methods, such as collisional activated dissociation (CAD) and infrared multiphoton dissociation (IRMPD), applied to protonated oligosaccharides results in predominantly glycosidic cleavages. However, oligosaccharides ionized with alkali, alkaline earth, and transition metals often fragment to yield more cross-ring cleavages compared to their protonated counterparts [11-14]. Although fragmentation of neutral oligosaccharides in negative-ion mode is not as frequently examined, it has been demonstrated that native, neutral oligosaccharide anions produce abundant C-type glycosidic cleavages and A-type cross-ring cleavages in CAD, as opposed to B- and Y-type glycosidic cleavages, which are commonly observed for oligosaccharide cations (Domon and Costello nomenclature [15]) [16-19]. Low-energy CAD combined with negative-ion mode electrospray ionization (ESI) has been used to examine neutral glycans from human urine and milk [19-22]. Less work has been done on negatively charged N-linked glycans, but it has been shown that neutral, singly deprotonated $\mathrm{N}$-glycans are highly susceptible to in-source fragmentation during electrospray ionization [23].

Many oligosaccharides derived from glycoproteins and glycolipids contain sialic acids, monosaccharides that contain a carboxylic acid group at the C-1 position. Oligosaccharides containing sialic acids typically yield more abundant signal in negative-ion mode mass spec- 
trometry. When sialylated oligosaccharides are analyzed in positive-ion mode, sialic acids may be lost, resulting in an absence of information regarding sialic acid linkage [5, 6]. Native sialylated oligosaccharides are particularly fragile in matrix-assisted laser desorption/ionization (MALDI) in which they often undergo in-source fragmentation, thereby suggesting electrospray ionization is more suitable for their analysis. The influence of sialylation on negative-ion mode CAD for milk and Nlinked oligosaccharides has been recently examined [24]. These results demonstrated that deprotonated sialylated oligosaccharides required more energy to fragment compared to either their deprotonated asialo or nitrate adducted counterparts. Zaia and coworkers [24] explain that sialylated glycans are more stable in the gas phase because negative charge resides on the carboxyl group. However, for asialo oligosaccharides, a proton is extracted from a ring hydroxyl group during electrospray ionization, which imparts more energy than it would for a sialylated oligosaccharide.

Although most modern mass analyzers use lowenergy dissociation techniques such as low-energy CAD, several alternative fragmentation techniques have been developed and applied to oligosaccharides, including high-energy CAD [25-27], IRMPD [28, 29], electron capture dissociation (ECD) [30, 31], electron detachment dissociation (EDD) [32, 33], and 157-nm photodissociation [34]. In particular, the use of ionelectron reactions for biomolecular structural characterization is rapidly expanding. ECD has been used extensively for the characterization of peptide and protein cations [35], due to its ability to promote extensive backbone fragmentation without loss of labile modifications such as glycosylation [36-41]. In ECD, polycationic molecules are irradiated with low-energy electrons $(<1 \mathrm{eV})$, generating charge-reduced radical species and product ions [42, 43]. ECD has been applied to protonated chitooligosaccharides, which yielded primarily glycosidic cleavages corresponding to B- and C-type ions [30], and recently to permethylated oligosaccharides [44]. We have demonstrated that ECD of oligosaccharides ionized with divalent metal ions can result in additional fragmentation not observed following vibrational excitation [31].

Electron detachment dissociation (EDD) was introduced in 2001 as a fragmentation technique for polyanions [45]. In EDD, polyanions are irradiated with $>10$ eV electrons, resulting in electron detachment and subsequent product ions. EDD has been applied to peptides [45-47], oligonucleotides [48, 49], gangliosides [50], and recently glycosaminoglycans (GAGs) [32, 33]. GAGs are linear polysaccharides consisting of repeating disaccharide units and are frequently polysulfated. EDD of GAGs resulted in information-rich mass spectra with both cross-ring and glycosidic cleavages. In contrast, CAD and IRMPD of GAGs resulted in predominantly glycosidic cleavages.

EDD has, to our knowledge, not previously been applied to a wide variety of oligosaccharides, including neutral and sialylated glycans, as well as branched oligosaccharides. In the current study, we examine the fragmentation patterns of neutral and sialylated oligosaccharides following EDD and compare these fragmentation patterns to those obtained from IRMPD and CAD. In addition, both linear and branched oligosaccharides are examined to determine what effect branching has on EDD fragmentation.

\section{Experimental}

\section{Sample Preparation}

Maltoheptaose (Sigma, St. Louis, MO), LS-tetrasaccharides (LSTa and LSTb), disialyllacto- $N$-tetraose (DSLNT), an asialo biantennary glycan (NA2; V-Labs, Covington, LA), and a monosialylated biantennary glycan (A1F; Calbiochem, San Diego, CA) were prepared in a solution of 50\% methanol (Fisher, Fair Lawn, NJ) and 0.1\% ammonium hydroxide (Sigma) to a final concentration of $3 \mu \mathrm{M}$.

\section{Mass Spectrometry}

All experiments were performed with an actively shielded 7-T Fourier transform ion cyclotron resonance (FT-ICR) mass spectrometer with a quadrupole frontend (APEX-Q, Bruker Daltonics, Billerica, MA), as previously described [51]. Samples were infused by an Apollo II ion source at a flow rate of $60 \mu \mathrm{L} / \mathrm{h}$ with the assistance of $\mathrm{N}_{2}$ nebulizing gas. Following ion accumulation in the first hexapole for $0.05 \mathrm{~s}$, ions were mass selectively accumulated in the second hexapole for 2-6 s. Ions were then transferred through high-voltage ion optics and captured with dynamic trapping in an Infinity ICR cell [51]. The experimental sequence up to the ICR cell fill was looped 4-8 times to achieve maximum precursor ion signal for EDD. Precursor ions were further isolated in the ICR cell using correlated harmonic excitation fields (CHEF) [52]. An indirectly heated hollow dispenser cathode was used to perform EDD [53]. IRMPD was performed with a vertically mounted 25-W, 10.6- $\mu \mathrm{m}, \mathrm{CO}_{2}$ laser (Synrad, Mukilteo, WA). External CAD was performed in a hexapole following mass selective ion accumulation with argon as a collision gas. For EDD, the cathode heating current was kept constant at 2.0 A and the cathode voltage was pulsed during the EDD event to a bias voltage of -20 to $-30 \mathrm{~V}$ for 1-2 s. A lens electrode located immediately in front of the cathode was kept $0.8-1 \mathrm{~V}$ higher than the cathode bias voltage.

\section{Data Analysis}

All mass spectra were acquired with XMASS software (Bruker Daltonics) with 256k data points and summed over 30 scans. Data processing was performed with MIDAS software [54]. Data were zero filled once, Hanning apodized, and exported to Microsoft Excel for 
internal frequency-to-mass calibration with a two-term calibration equation. The precursor ion and chargereduced radical species were used for calibration of EDD spectra. For CAD, IRMPD, and EDD spectra where the charge-reduced species was not observed (or with only low abundance), an abundant glycosidic cleavage product ion and the precursor were used for calibration. Product ion spectra were interpreted with the aid of the web application GlycoFragment (www. dkfz.de/spec/projekte/fragments /) [55].

\section{Results and Discussion}

All product ions are labeled according to the Domon and Costello nomenclature [15]. Ions arising from multiple cleavage sites are designated with a slash between sites of cleavage (e.g., ${ }^{2,4} A_{6} / Y_{5}$ ). When several product ion assignments are possible, alternative assignments are indicated in parentheses [e.g., $\mathrm{Y}_{4 \alpha}\left(\mathrm{Y}_{3 \beta}\right)$ ]. For branched oligosaccharides, the letter $\alpha$ represents the largest branch.

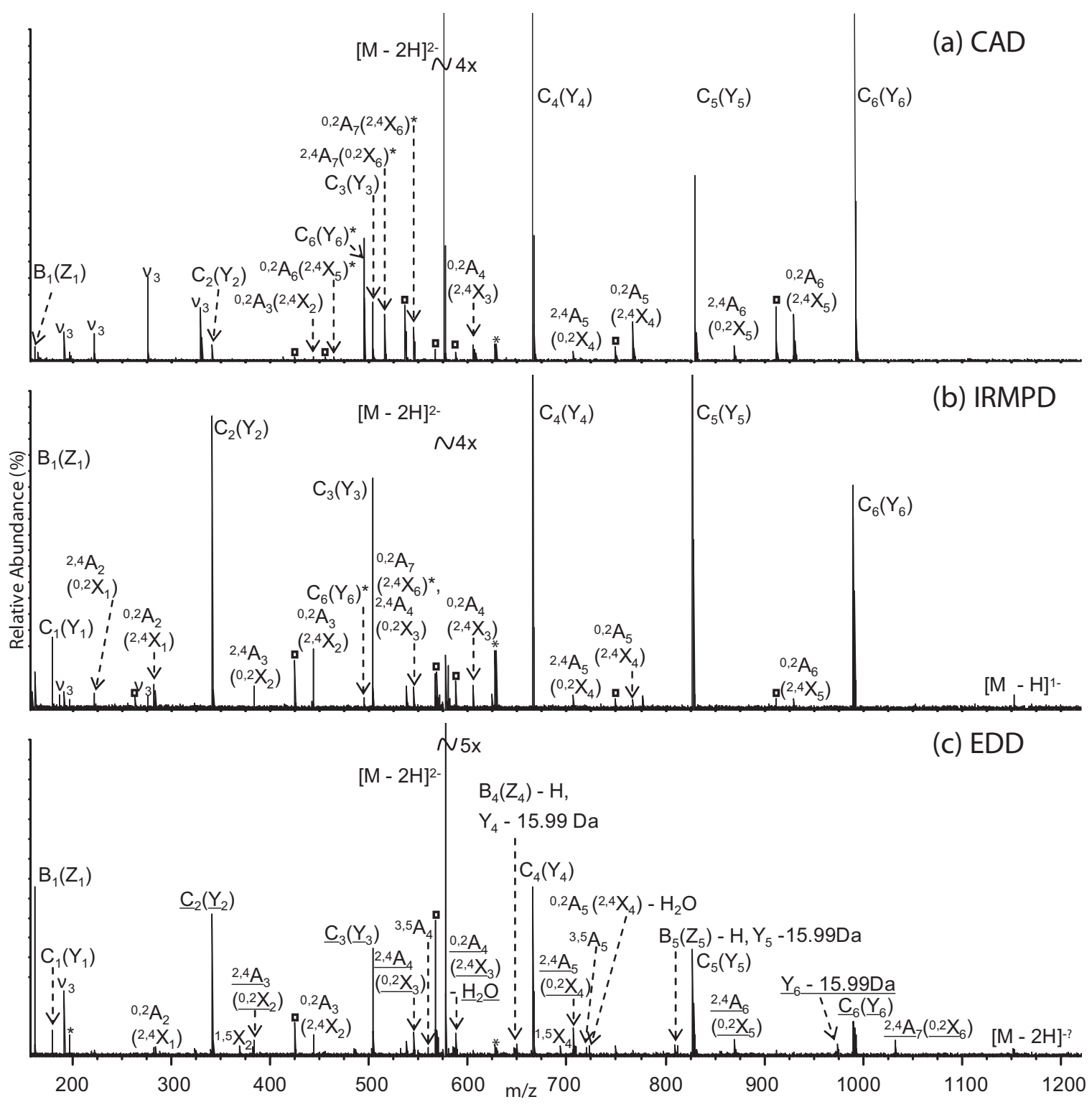

Figure 1. FT-ICR tandem mass spectra of doubly deprotonated maltoheptaose: (a) CAD (30 scans, collision cell voltage $3 \mathrm{~V}$ ); (b) IRMPD (30 scans, $200 \mathrm{~ms}$ irradiation, $2.5 \mathrm{~W}$ ); (c) EDD (30 scans, $2 \mathrm{~s}$, bias voltage of $-25 \mathrm{~V}$ ). Doubly deprotonated product ions are indicated with an asterisk next to a product ion assignment. Asterisks above a peak indicate electronic noise. Squares indicate water loss from an adjacent product ion. Underlined product ions exhibit minor radical species (with a mass corresponding to hydrogen loss). Due to the symmetry of the molecule, several product ions cannot be unambiguously assigned (indicated by parentheses in the labels in each spectrum). 


\section{MS/MS of Neutral Oligosaccharides}

Two neutral oligosaccharides were examined to evaluate the EDD fragmentation patterns of oligosaccharides lacking acidic moieties. These oligosaccharides include maltoheptaose, a linear oligosaccharide containing seven $\alpha 1 \rightarrow 4$ linked glucose molecules (Figure 1 and Scheme 1), and an asialo, biantennary glycan (NA2) with a composition of Gal $\beta 4$ GlcNAc $\beta 2$ Man $\alpha 6$ (Gal/34GlcNAc(32Man $\alpha 3$ )Man $\beta 4$ GlcNAc $\beta 4$ GlcNAc (Figure 2 and Scheme 2). Due to the symmetric nature of maltoheptaose, a number of ions cannot be distinguished based on their $\mathrm{m} / \mathrm{z}$ ratios ( $\mathrm{C}$ and $\mathrm{Y}$, and several $\mathrm{A}$ and $\mathrm{X})$. However, native neutral oligosaccharide anions that are $1 \rightarrow 4$ or $1 \rightarrow 6$ linked have been shown to produce predominantly C-type and A-type ions during CAD [16-20]. The majority of ions observed following CAD (Figure 1a) and IRMPD (Figure 1b) of maltoheptaose are singly charged, with exceptions being denoted by an asterisk. The CAD and IRMPD spectra show very similar fragmentation patterns, although they are not identical. Several lower molecular weight glycosidic and cross-ring cleavage product ions were observed only following IRMPD. Although IRMPD and lowenergy CAD are both low-energy vibrational excitation techniques, Lebrilla and coworkers have shown that the fragmentation efficiency in IRMPD is greater than that in CAD for larger oligosaccharides [56]. An alternative explanation for the absence of low molecular weight species following CAD is the time-of-flight effect when

\section{(a) CAD}

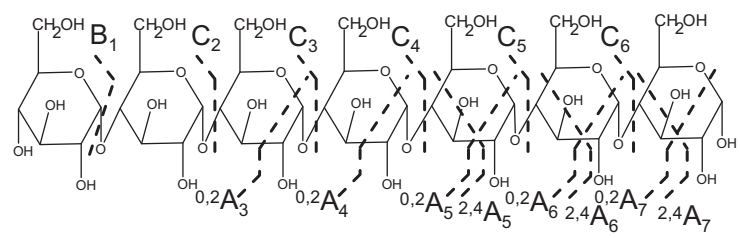

(b) IRMPD

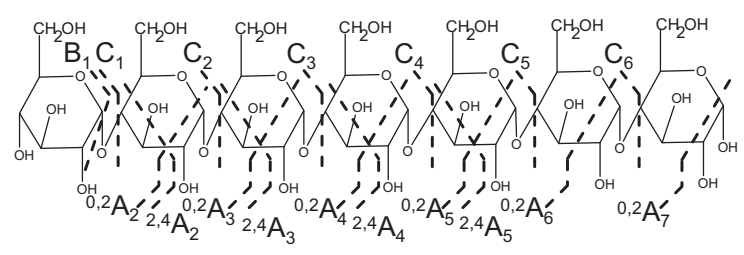

(c) EDD

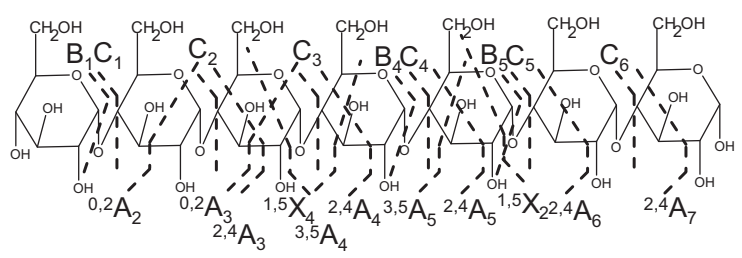

Scheme 1. Fragmentation patterns observed following CAD, IRMPD, and EDD of doubly deprotonated maltoheptaose. transferring ions from the external hexapole to the ICR cell. Low $\mathrm{m} / \mathrm{z}$ species will arrive at the cell sooner than higher $\mathrm{m} / \mathrm{z}$ species, thereby displaying optimum capture at different experimental conditions. Cross-ring cleavages observed following both fragmentation techniques corresponded either to ${ }^{0,2} \mathrm{~A}$-type or ${ }^{2,4} \mathrm{~A}$-type ions, consistent with $\alpha 1 \rightarrow 4$ linked saccharides. CAD and IRMPD of singly deprotonated maltoheptaose were also examined (see Supplementary Material section, which can be found in the online version of this article.). Product ions observed from the $[\mathrm{M}-\mathrm{H}]^{-}$species were very similar to those from the $[\mathrm{M}-2 \mathrm{H}]^{2-}$ precursor ions. Although maltoheptaose is a neutral oligosaccharide, under the negative-ion mode electrospray conditions used here, the relative abundance of the doubly deprotonated species was typically at least $50 \%$. Thus, EDD of this neutral oligosaccharide was not hindered by poor ion signal.

The EDD spectrum of doubly deprotonated maltoheptaose (Figure 1c) contains only singly charged product ions, including the charge-reduced species, [M $2 \mathrm{H}]^{-\cdot}$. Singly charged product ions can arise by two fragmentation mechanisms, either through direct decomposition of the activated precursor ion or through electron detachment from the precursor and subsequent fragmentation [32]. A mixture of even- and odd-electron species is observed following EDD of maltoheptaose. Ions that exhibit minor hydrogen loss, resulting in odd-electron species, are underlined in Figure 1c. For these product ions, hydrogen loss was a relatively minor fragmentation pathway. One exception is the ion at $m / z 646.2$, denoted $\mathrm{B}_{4}\left(\mathrm{Z}_{4}\right)-\mathrm{H}$, in which the radical species is more abundant than the even-electron species. Product ions corresponding to loss of hydrogen from B-type ions have also observed following EDD of GAGs [32]. Odd-electron product ions can be formed following hydrogen loss from an even-electron species, or can be formed directly following fragmentation of the charge-reduced radical species.

EDD of maltoheptaose results in a combination of glycosidic and cross-ring fragmentation, and exhibits several unique product ions not observed following either CAD or IRMPD. In addition to several ${ }^{0,2} \mathrm{~A}\left({ }^{2,4} \mathrm{X}\right)$ and ${ }^{2,4} \mathrm{~A}\left({ }^{0,2} \mathrm{X}\right)$-type cross-ring cleavages, ${ }^{1,5} \mathrm{X}$ and ${ }^{3,5} \mathrm{~A}$ type ions are observed, including ${ }^{1,5} \mathrm{X}_{2},{ }^{1,5} \mathrm{X}_{4},{ }^{3,5} \mathrm{~A}_{4}$, and ${ }^{3,5} \mathrm{~A}_{5}$. Both ${ }^{1,5} \mathrm{X}$ and ${ }^{3,5} \mathrm{~A}$-type cross-ring cleavages are commonly observed following positive-ion mode highenergy CAD (heCAD) of oligosaccharides [27, 57], and were also noted following EDD of GAGs [32]. X-type cross-ring cleavages are typically not observed following low-energy CAD or IRMPD.

Three unique product ions, denoted $\mathrm{Y}_{4}-15.99 \mathrm{Da}$, $\mathrm{Y}_{5}-15.99 \mathrm{Da}$, and $\mathrm{Y}_{6}-15.99 \mathrm{Da}$, were observed following EDD of maltoheptaose. These ions were not reported by Amster and coworkers following EDD of GAGs. Kováčik et al. [58] and Harvey et al. [57] have reported $\mathrm{Y}-16 \mathrm{Da}$ ions following positive-ion mode heCAD. In their experiments, only $\mathrm{Y}-16 \mathrm{Da}$ ions were observed, as opposed to C $-16 \mathrm{Da}$ (a possible alterna- 


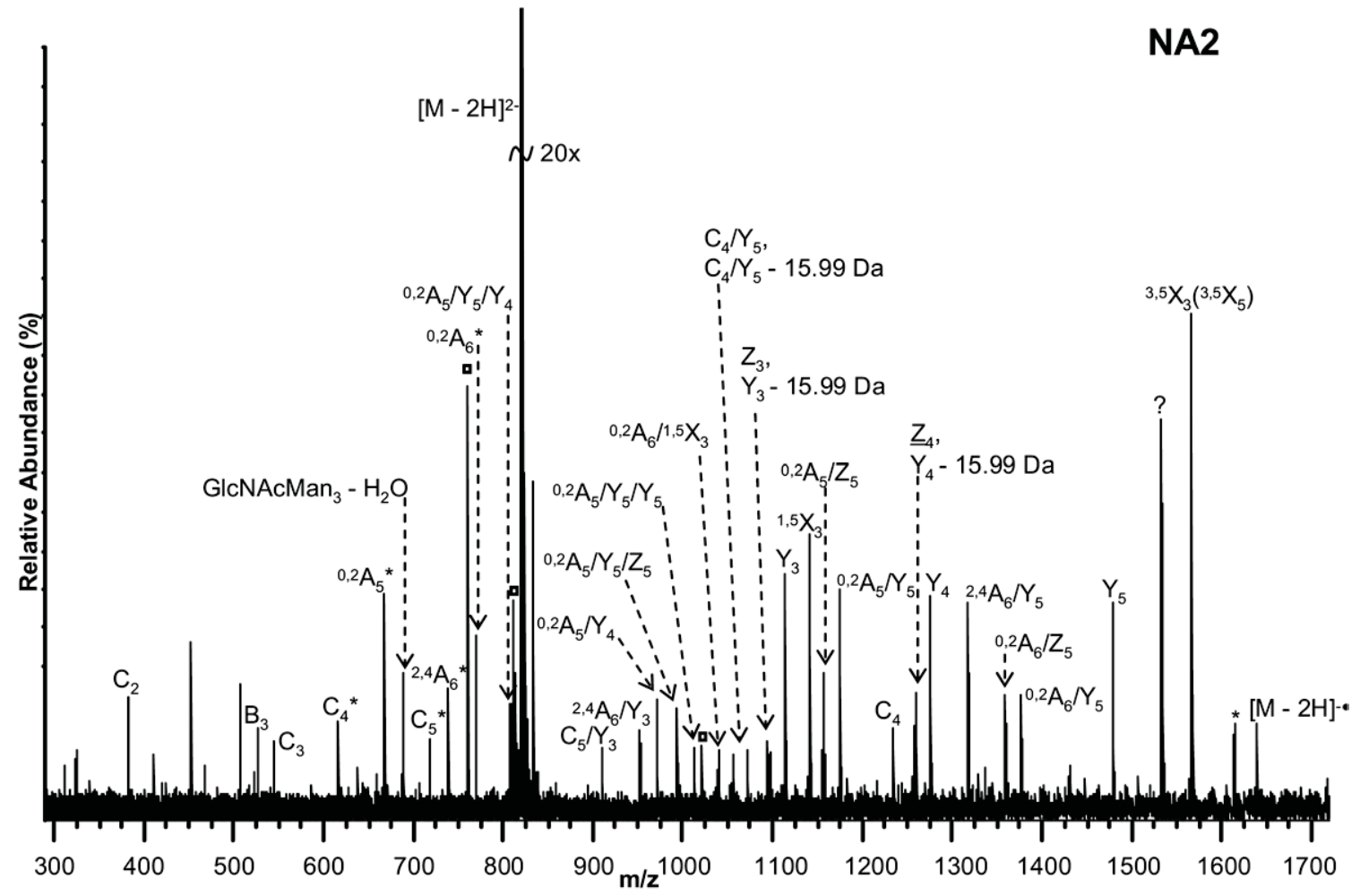

Figure 2. EDD (30 scans, $1 \mathrm{~s}$, bias voltage of $-25 \mathrm{~V}$ ) of a doubly deprotonated asialo, biantennary glycan (NA2). Doubly deprotonated product ions are indicated with an asterisk next to a product ion assignment. Asterisks above a peak indicate electronic noise. Squares indicate water loss from an adjacent product ion. Underlined product ions exhibit minor radical species (with a mass corresponding to loss of hydrogen). Ions due to multiple cleavage sites are designated with a slash between sites of cleavage. Product ions which cannot be unambiguously assigned are indicated by parentheses in the labels.

tive assignment due to the symmetry of maltoheptaose). However, following EDD of other neutral and sialylated oligosaccharides (discussed below), only losses of 16 mass units are observed from Y-type ions. We propose that these ions correspond to $\mathrm{Z}+2 \mathrm{H}$ ions. Kováčik et al. proposed that these ions were due to internal residue losses. However, for maltoheptaose, internal residue loss would not account for the molecular weight of these product ions. The same authors also discussed that these product ions could correspond to $\mathrm{Z}+2 \mathrm{H}$ ions, but later disregarded this explanation. We believe there are several lines of evidence to support that these ions observed following EDD are $\mathrm{Z}+2 \mathrm{H}$ species. Hydrogen addition and abstraction following ECD of peptides have been well documented [60, 59], and have also been reported for EDD of peptides [45]. Following EDD of GAGs, hydrogen abstraction from Band C-type ions has also been noted, and observed as B $-\mathrm{H}, \mathrm{C}-\mathrm{H}$, and $\mathrm{C}-2 \mathrm{H}$ type ions [32,33]. Of particular interest is the product ion type $\mathrm{C}-2 \mathrm{H}$, which also has been reported by several investigators following positive-ion mode heCAD [58, 61-64] and which is observed following EDD of sialylated oligosaccharides in our examination. The complementary fragment for a $\mathrm{C}-2 \mathrm{H}$ product ion would be a $\mathrm{Z}+2 \mathrm{H}$ species. For both maltoheptaose and an asialo biantennary glycan (NA2) (Figure 2), $\mathrm{Z}+2 \mathrm{H}$ (or $\mathrm{Y}-16 \mathrm{Da}$ ) product ions are observed, whereas their complementary $\mathrm{C}-2 \mathrm{H}$ species are absent.

CAD and IRMPD spectra of a doubly deprotonated asialo, biantennary glycan (NA2) are shown in the Supplementary Material section. The corresponding singly deprotonated species was of relatively poor abundance $(<5 \%)$ following ESI and was not examined.

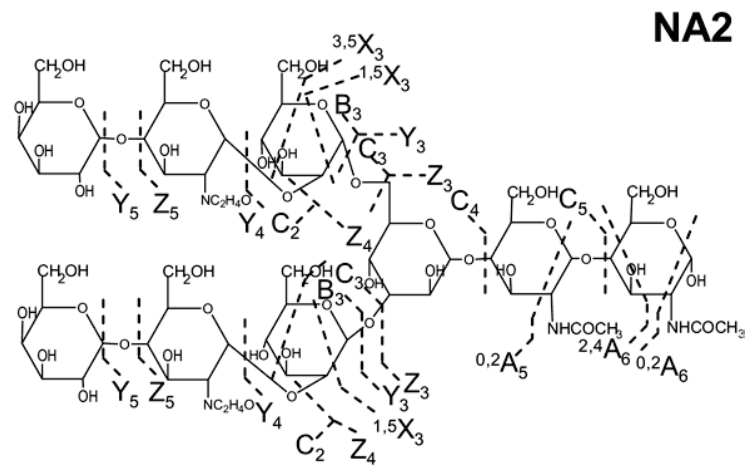

Scheme 2. Fragmentation pattern observed following EDD of a doubly deprotonated asialo, biantennary glycan (NA2). 


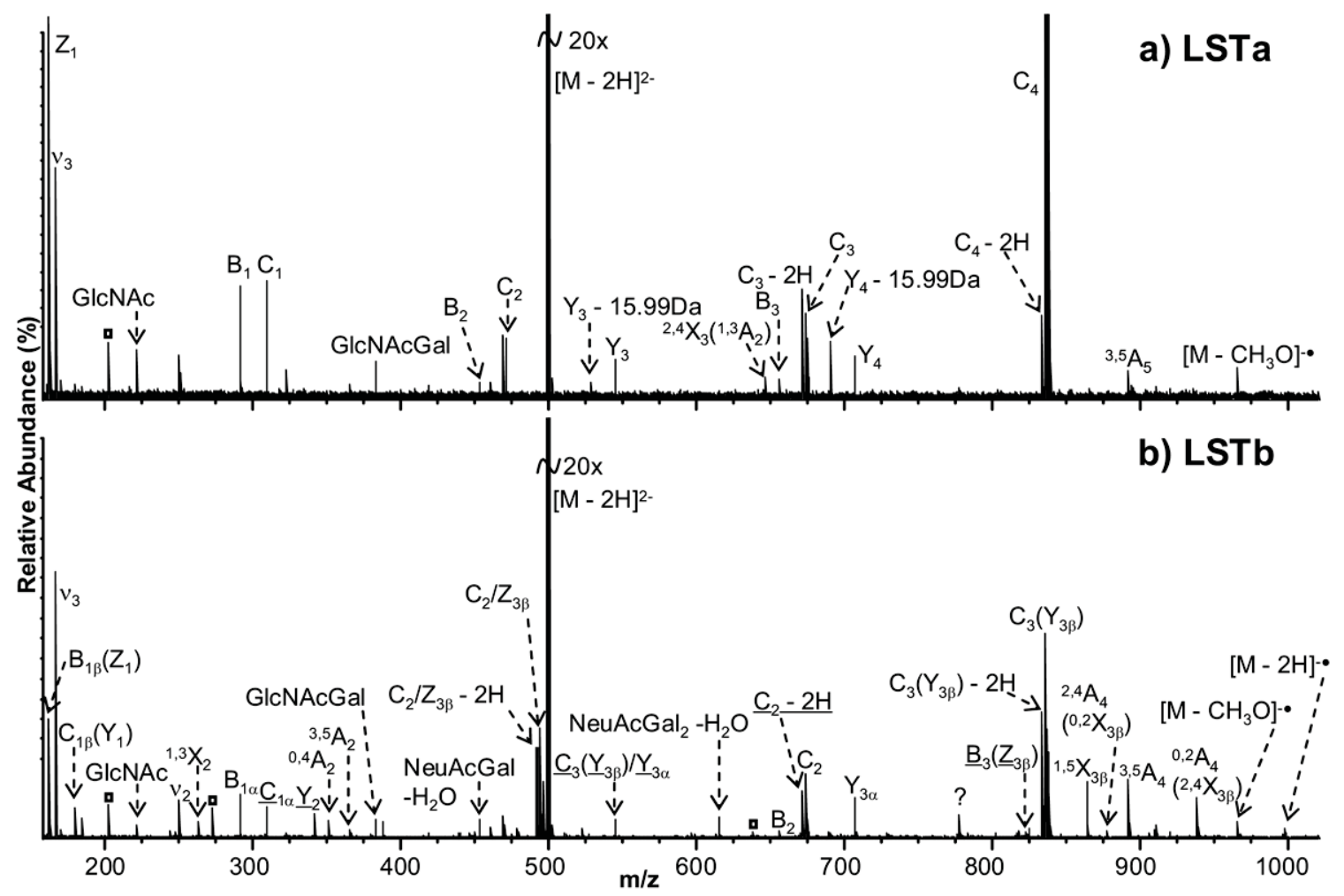

Figure 3. EDD of doubly deprotonated oligosaccharides: (a) LSTa (30 scans, $1 \mathrm{~s}$, bias voltage of $-30 \mathrm{~V}$ ) and (b) LSTb (30 scans, $1 \mathrm{~s}$, bias voltage of $-25 \mathrm{~V}$ ). Squares indicate water loss from an adjacent product ion. Underlined product ions exhibit minor radical species (with a mass corresponding to loss of hydrogen). Ions due to multiple cleavage sites are designated with a slash between sites of cleavage. Product ions which cannot be unambiguously assigned are indicated by parentheses in the labels. The branch containing sialic acid is referred to as the $\alpha$-branch in product ion labels.

Both CAD and IRMPD of the doubly deprotonated species resulted in a mixture of glycosidic and crossring cleavages, where glycosidic cleavages included both C- and B-type ions (which could also correspond to water losses from C-type ions). Cross-ring fragments were almost exclusively ${ }^{0,2} \mathrm{~A}$ and ${ }^{2,4} \mathrm{~A}$-type ions. The singly deprotonated glycan has also been examined in negative-ion mode CAD following ESI by Harvey [65] and by Zaia and coworkers [24], showing a fragmentation pattern similar to that of the doubly deprotonated species examined here.

Unlike maltoheptaose, a mixture of doubly and singly charged product ions was observed following EDD of NA2 (Figure 2 and Scheme 2). Doubly charged product ions, including $\mathrm{C}_{4}{ }^{*}, \mathrm{C}_{5}{ }^{*},{ }^{0,2} \mathrm{~A}_{5}{ }^{*},{ }^{0,2} \mathrm{~A}_{6}{ }^{*}$, and ${ }^{2,4} \mathrm{~A}_{6}{ }^{*}$, are likely due to direct decomposition of the activated precursor ion. The majority of product ions generated following EDD are even-electron species. Several product ions are due to multiple cleavages, many of which involve a combination of glycosidic and cross-ring fragmentation. In addition to ${ }^{2,4} \mathrm{~A}$ and ${ }^{0,2} \mathrm{~A}-$ type cross-ring cleavages, ${ }^{1,5} \mathrm{X}$ and ${ }^{3,5} \mathrm{X}$-type product ions were observed. One of the most abundant product ions detected following EDD corresponds to ${ }^{3,5} \mathrm{X}_{3}\left({ }^{3,5} \mathrm{X}_{5}\right)$, at $m / z$ 1565.55. Also observed is the product ion at $\mathrm{m} / \mathrm{z}$ 688.23 labeled GlcNAcMan $3-\mathrm{H}_{2} \mathrm{O}$, otherwise known
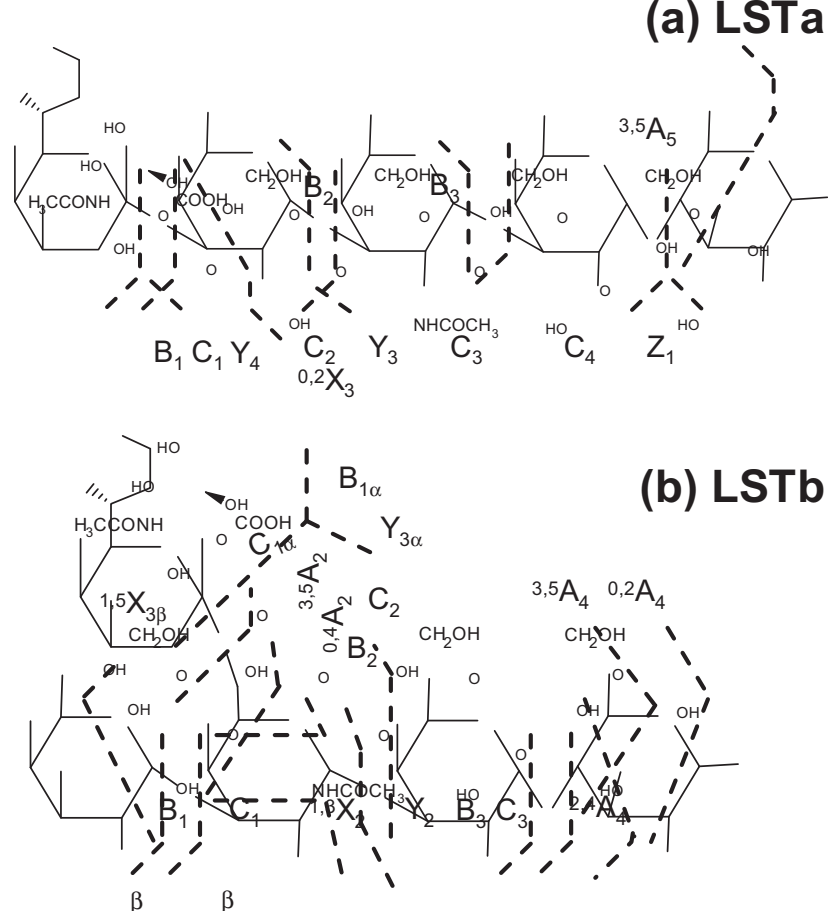

Scheme 3. Fragmentation patterns observed following EDD of the doubly deprotonated oligosaccharides LSTa and LSTb. 


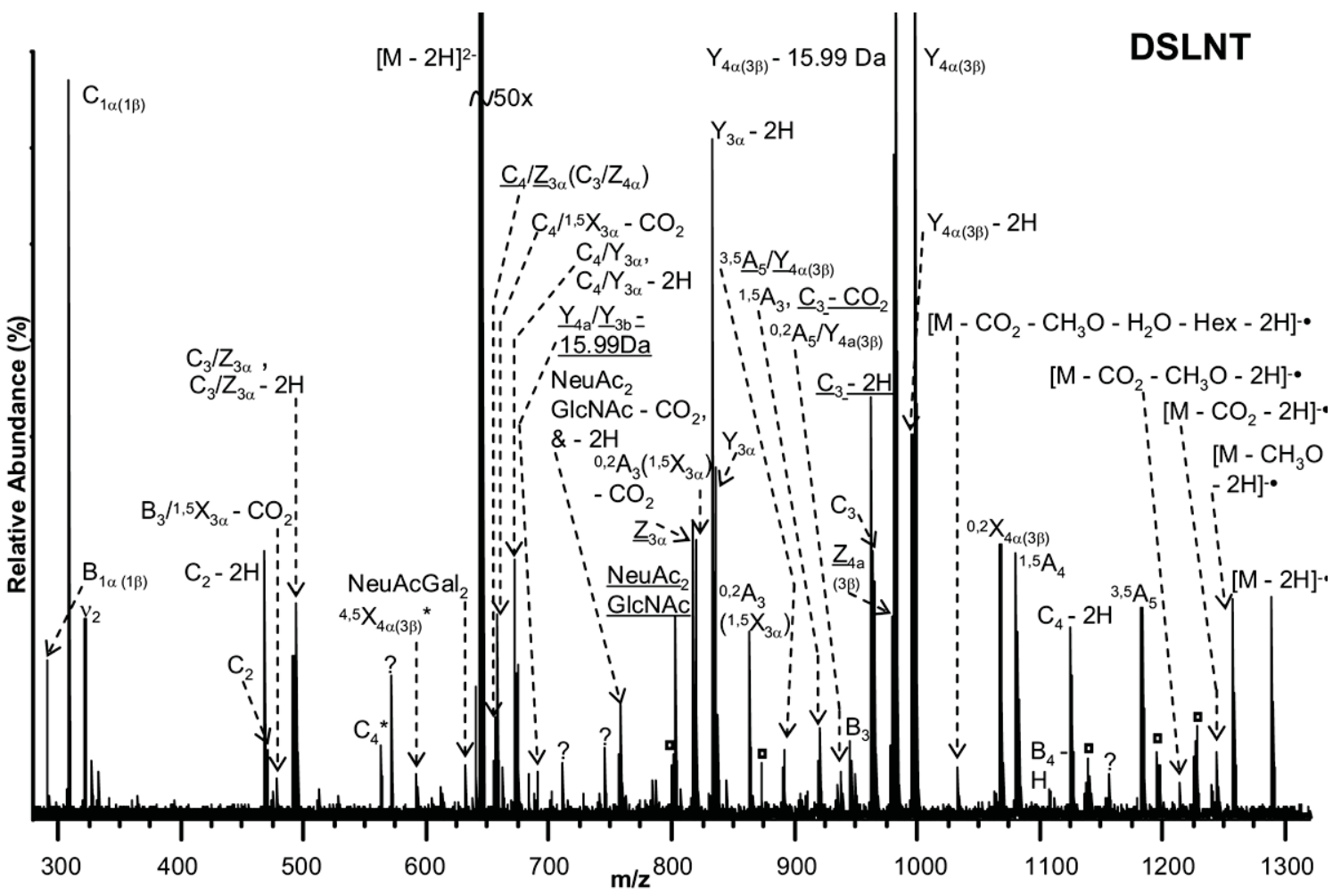

Figure 4. EDD of doubly deprotonated DSLNT (30 scans, $2 \mathrm{~s}$, bias voltage of $-20 \mathrm{~V}$ ). Squares indicate water loss from an adjacent product ion. Doubly deprotonated product ions are indicated with an asterisk next to a product ion assignment. Underlined product ions exhibit minor radical species (with a mass corresponding to loss of hydrogen). Ions due to multiple cleavage sites are designated with a slash between sites of cleavage. Product ions which cannot be unambiguously assigned are indicated by parentheses in the labels. The $\alpha$-branch refers to the heavier branch, containing sialic acid and galactose.

as "ion D." This ion is due to loss of the 3-linked antenna and two reducing GlcNAc residues. Ion D allows for determination of the monosaccharide composition of the 6-linked antenna, and by subtraction also the 3-linked antenna. This ion was also observed following IRMPD and CAD. Two Y - 16 Da type ions, or as we propose $\mathrm{Z}+2 \mathrm{H}$ ions, are also observed following EDD (denoted as $\mathrm{Y}_{4}-15.99 \mathrm{Da}$ and $\mathrm{C}_{4} / \mathrm{Y}_{5}-15.99 \mathrm{Da}$ ). Similar to maltoheptaose, $\mathrm{C}-2 \mathrm{H}$ ions were not detected following EDD.

\section{MS/MS of Sialylated Oligosaccharides}

The CAD, IRMPD, and EDD fragmentation patterns of four sialylated oligosaccharides were next examined. All IRMPD and CAD spectra are shown in the Supplementary Material section. The first oligosaccharide examined, LSTa, is a linear oligosaccharide with the composition Neu5Ac $\alpha 3$ Gal $\beta 3$ GlcNAc $\beta 3$ Gal$\beta 4$ Glc (Figure 3a and Scheme 3a). A related branched oligosaccharide, LSTb, in which the sialic acid is instead $\alpha 2 \rightarrow 6$ linked to GlcNAc (Figure $3 b$ and Scheme $3 b$ ) was also examined. The third oligosaccharide, a disialyllacto-N-tetraose oligosaccharide (DSLNT), is similar to LSTa but with a second sialic acid $\alpha 2 \rightarrow 6$ linked to GlcNAc (Figure 4 and Scheme 4). The last oligosaccha- ride examined was an $\mathrm{N}$-linked monosialylated, biantennary glycan (A1F), with the composition Neu5Aca3 / 6Gal $\beta 4$ GlcNAc $\beta 2$ Man $\alpha 6$ (Gal $\beta 4$ GlcNAc $\beta 2-$ Man $\alpha 3$ Man $\beta 4$ GlcNAc $\beta 4$ (Fuc $\alpha 6$ )-GlcNAc (Figure 5 and Scheme 5).

CAD and IRMPD of both singly and doubly deprotonated LSTa were examined. Under standard negativeion mode electrospray ionization conditions, the average relative abundance of doubly deprotonated LSTa

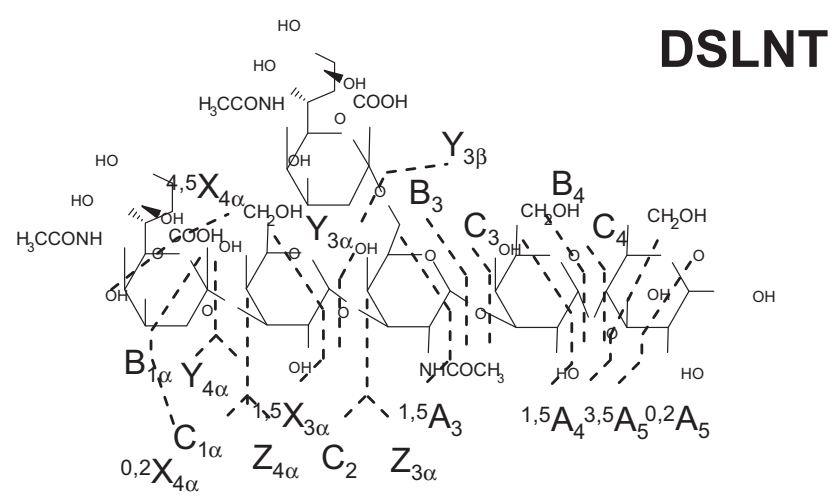

Scheme 4. Fragmentation pattern observed following EDD of doubly deprotonated DSLNT. 


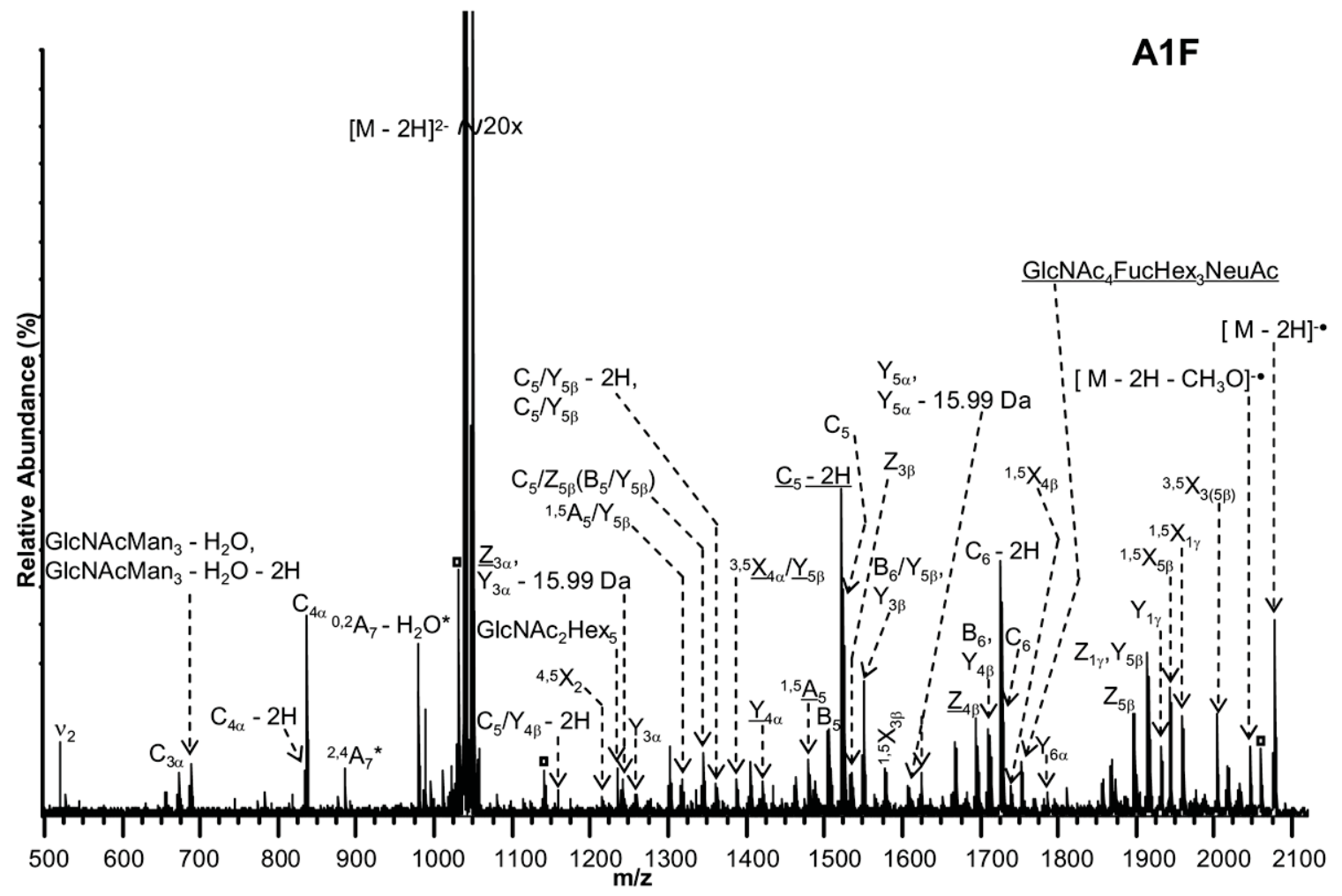

Figure 5. EDD of doubly deprotonated A1F (30 scans, $2 \mathrm{~s}$, bias voltage of $-30 \mathrm{~V}$ ). Squares indicate water loss from an adjacent product ion. Underlined product ions exhibit minor radical species (with a mass corresponding to loss of hydrogen). Ions due to multiple cleavage sites are designated with a slash between sites of cleavage. Product ions which cannot be unambiguously assigned are indicated by parentheses in the labels.

was $30 \%$. Although generation of this doubly deprotonated species is more difficult compared to maltoheptoase or the branched NA2 glycan, EDD of this species was facilitated by longer accumulation times and increased numbers of cell fills. CAD and IRMPD of both singly and doubly deprotonated LSTa resulted in ${ }^{0,2} \mathrm{~A}$ and ${ }^{2,4} \mathrm{~A}$ cross-ring cleavages in the reducing end glucose (see Supplementary Material section). Cross-ring cleavage in the reducing terminal residue and for internal 4-linked residues are commonly observed in negative-ion mode low-energy vibrational excitation fragmentation [15, 19, 20]. In addition, glycosidic cleavage (predominantly resulting in C-type ions) was observed between every residue. As has been shown for sialylated oligosaccharides by Zaia and coworkers [24], singly deprotonated LSTa required more energy for fragmentation during CAD compared to the energies used for asialo oligosaccharides previously discussed $(30 \mathrm{~V}$ for LSTa versus 8-14 V for maltoheptaose and NA2).

Only singly charged product ions were observed following EDD of LSTa (Figure 3a). Glycosidic cleavage was noted between every pair of saccharide residues and two cross-ring cleavage products, ${ }^{2,4} \mathrm{X}_{3}\left({ }^{1,3} \mathrm{~A}_{2}\right)$ and ${ }^{3,5} \mathrm{~A}_{5}$ were also observed following EDD. These crossring cleavages were not seen following CAD or IRMPD of either the singly or doubly deprotonated species. Loss of $\mathrm{CH}_{3} \mathrm{O}$ from the charge reduced species has been previously detected following EDD of GAGs. It is also interesting to note that both $\mathrm{Y}-16$ Da species $\left(\mathrm{Y}_{3}-\right.$ $15.99 \mathrm{Da}$ and $\left.\mathrm{Y}_{4}-15.99 \mathrm{Da}\right)$ and $\mathrm{C}-2 \mathrm{H}$ species $\left(\mathrm{C}_{3}-\right.$ $\left.2 \mathrm{H}, \mathrm{C}_{4}-2 \mathrm{H}\right)$ are observed following EDD.

As previously discussed, $\mathrm{C}-2 \mathrm{H}$ species have been reported in several instances following heCAD in positive-ion mode and recently following EDD of

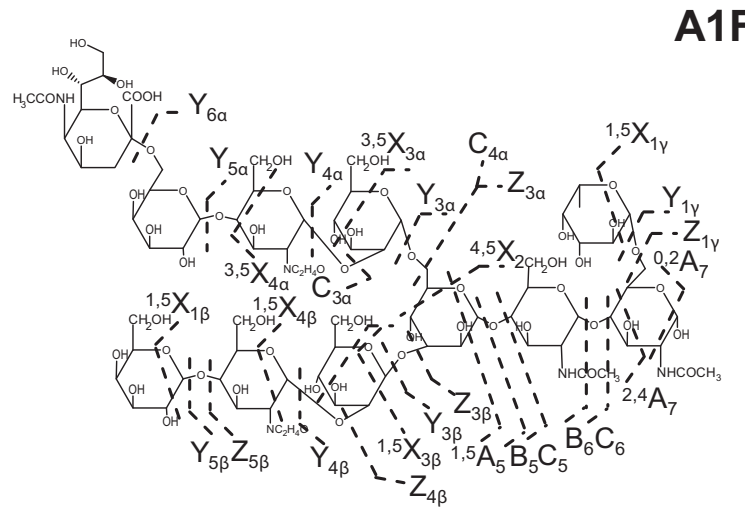

Scheme 5. Fragmentation pattern observed following EDD of a doubly deprotonated A1F glycan. This glycan sample contains both $2 \rightarrow 3$ and $2 \rightarrow 6$ linked sialic acid, but only the $2 \rightarrow 6$ linkage is shown in the diagram above. The $\alpha$-branch contains the sialic acid residue whereas the $\gamma$-branch contains fucose. 
GAGs. During positive-ion mode heCAD, the precise mechanism that generates these ions is somewhat unclear [58]. In EDD, Wolff et al. have proposed that electron detachment at a carboxylate group is followed by hydrogen transfer to form either an oxy radical at C-2 or a radical at C-3, which can lead to the formation of $\mathrm{C}-$ $2 \mathrm{H}$ product ions by $\alpha$-cleavage [33]. Following EDD of GAGs, the complementary $\mathrm{Z}+2 \mathrm{H}$ ions (or $\mathrm{Y}-16 \mathrm{Da}$ species) were not observed. In our experiments, such species were observed following EDD of maltoheptaose and NA2, whereas the $\mathrm{C}-2 \mathrm{H}$ species were absent. This observation may be due to differences in the sites of deprotonation in neutral versus acidic oligosaccharides. For the neutral oligosaccharides examined, both sites of deprotonation should be hydroxyl groups. The allylic hydroxyl hydrogen [66] on C-1 and the C-3 hydroxyl hydrogen [67] have been shown to be acidic sites. LSTa, which contains one sialic acid, most likely has one deprotonation site at the carboxylate group, whereas the other site should be a hydroxyl group.

CAD and IRMPD spectra of doubly and singly deprotonated LSTb showed relatively similar fragmentation patterns (see Supplementary Material section). The relative abundance of doubly deprotonated LSTb was similar to that of LSTa, and EDD was facilitated by longer accumulation times and increased numbers of cell fills. CAD and IRMPD of the singly and doubly deprotonated species exhibited ${ }^{0,2} \mathrm{~A}$ and ${ }^{2,4} \mathrm{~A}$-type cleavage in the reducing terminal glucose. The majority of observed product ions retained sialic acid and two of the most informative product ions observed were $C_{2}$ / $Z_{3 \beta}$ (D-type cleavage) and ${ }^{0,4} A_{2}$. Residues that are $1 \rightarrow 3$ linked often produce $C$-type cleavage on the reducing side and Z-type cleavage on the non-reducing side in negative-ion mode [19]. Both of these ions provide information regarding the linkage position of sialic acid.

EDD of LSTb (Figure $3 b$ ) resulted in more extensive fragmentation compared to CAD and IRMPD of the singly and doubly deprotonated species. In addition to extensive glycosidic cleavage, several cross-ring cleavage product ions were observed following EDD. Along with ${ }^{0,2} \mathrm{~A}$ and ${ }^{2,4} \mathrm{~A}$-type cleavage within the reducing end glucose (which were also observed from IRMPD and $\mathrm{CAD}),{ }^{1,3} \mathrm{X},{ }^{3,5} \mathrm{~A}$, and ${ }^{1,5} \mathrm{X}$-type cleavages were also detected. Three cross-ring products were observed in the branching GlcNAc residue, including ${ }^{1,3} \mathrm{X}_{2},{ }^{3,5} \mathrm{~A}_{2}$, and ${ }^{0,4} A_{2}$. The ${ }^{0,4} A_{2}$ and ${ }^{3,5} A_{2}$ product ions indicate the attachment of sialic acid to $C-6$, whereas the ${ }^{1,3} X_{2}$ ion indicates a likely linkage position for the 3-linked galactose. Two hydrogen losses from several C-type ions (or hydrogen loss from a radical C-type ion) were also seen, including $\mathrm{C}_{2} / \mathrm{Z}_{3 \beta}-2 \mathrm{H}, \mathrm{C}_{2}-2 \mathrm{H}$, and $\mathrm{C}_{3}\left(\mathrm{Y}_{3}\right)-2 \mathrm{H}$. Two unique product ions, denoted NeuAcGal $-\mathrm{H}_{2} \mathrm{O}$ and $\mathrm{NeuAcGal}{ }_{2}-\mathrm{H}_{2} \mathrm{O}$ are also interesting to note in the EDD spectrum. These ions can be formed only by saccharide rearrangement. Other carbohydrates have also been shown to undergo rearrangement reactions with losses of internal saccharide residues during CAD [59, 68-70].
CAD and IRMPD of a doubly and singly deprotonated disialylated oligosaccharide (DSLNT) were examined. As expected, the relative abundance of the doubly deprotonated form was always much larger than that of the singly deprotonated form. CAD and IRMPD of the singly deprotonated species resulted in less fragmentation than the doubly deprotonated species. In CAD and IRMPD (see Supplementary data) of the doubly deprotonated species, both glycosidic and cross-ring cleavages were observed, similar to other oligosaccharides examined thus far. Both ${ }^{0,2} \mathrm{~A}$ and ${ }^{2,4} \mathrm{~A}$-type cleavages were present in the reducing terminal saccharide. Similar to IRMPD and CAD, several product ions observed following EDD (Figure 4) are due to multiple cleavages. Neutral losses from the charge reduced species are also quite extensive, with losses of $\mathrm{CO}_{2}$ and $\mathrm{CH}_{3} \mathrm{O}$ being the most predominant. In addition to a ${ }^{0,2} \mathrm{~A}$-type cleavage in the reducing terminal saccharide, several additional cross-ring cleavages are observed following EDD that were not present in CAD or IRMPD spectra. These correspond to ${ }^{3,5} \mathrm{~A},{ }^{1,5} \mathrm{~A},{ }^{0,2} \mathrm{X},{ }^{4,5} \mathrm{X}$, and ${ }^{1,5} \mathrm{X}$ type product ions. One of the most abundant product ions observed following EDD is at $m / z$ 977.34 $\left[\mathrm{Y}_{3 \alpha}\left(\mathrm{Y}_{3 \beta}\right)\right]$, due to loss of sialic acid. Another product ion is observed that is $2 \mathrm{Da}$ lighter, and would appear to correspond to a loss of two hydrogens from this Y-type ion (or loss of one hydrogen from the radical $\mathrm{Y}$-type species). $\mathrm{Y}-2 \mathrm{H}$ product ions have also been observed following positive mode heCAD and are likely formed by a mechanism similar to $\mathrm{C}-2 \mathrm{H}$ ions [62]. The product ion at $\mathrm{m} / \mathrm{z} 833.27$ has been assigned as a $\mathrm{Y}-2 \mathrm{H}$ type product ion $\left(\mathrm{Y}_{3 \mathrm{c}}-2 \mathrm{H}\right)$, but given that EDD of DSLNT resulted in significant internal cleavages, this ion could also be assigned $\mathrm{C}_{4} / \mathrm{Y}_{4}-2 \mathrm{H}$. Similar to other EDD spectra (Figures 1-3), $\mathrm{C}-2 \mathrm{H}, \mathrm{Y}-16 \mathrm{Da}$, and $\mathrm{B}-\mathrm{H}$ product ions are also seen following EDD of DSLNT. Many of these product ion types have been observed in heCAD, but only $\mathrm{C}-$ $2 \mathrm{H}$ and $\mathrm{B}-\mathrm{H}$ ions have been noted following EDD of GAGs. However, the electron energies used in our examination were higher $(20-30 \mathrm{eV})$ compared to those used in EDD of GAGs (19 eV), which may result in energy deposition more similar to that in heCAD.

The singly deprotonated sialylated N-linked glycan (A1F) was of relatively low abundance following negative mode electrospray ionization $(<5 \%)$, and was therefore not examined. CAD and IRMPD of the doubly deprotonated species (see Supplementary data) resulted in several glycosidic cleavages, which corresponded mainly to C- and B-type ions (which may also be due to water loss from C-type ions). ${ }^{0,2} \mathrm{~A}$ and ${ }^{2,4} \mathrm{~A}$-type cleavages were observed in both reducing terminal GlcNAc residues. These ions are useful for determining the presence of a core fucose residue. Fragmentation following EDD (Figure 5 and Scheme 5) was more extensive than either CAD or IRMPD, and resulted in several glycosidic and cross-ring product ions. The most abundant product ions correspond to $\mathrm{C}$-type cleavages. In many instances the $\mathrm{C}-2 \mathrm{H}$ species were more abundant than typical C-type product ions 
(for example, $\mathrm{C}_{6}-2 \mathrm{H}$ and $\mathrm{C}_{5}-\mathrm{H}$ ). This behavior is similar to what was observed in EDD of DSLNT. Similar to other EDD spectra of neutral and sialylated oligosaccharides (Figures 1-4), EDD of A1F resulted in several internal cleavages. Several additional cross-ring cleavages were observed following EDD compared to CAD and IRMPD, including those corresponding to ${ }^{1,5} \mathrm{X},{ }^{3,5} \mathrm{X},{ }^{4,5} \mathrm{X},{ }^{1,5} \mathrm{~A},{ }^{0,2} \mathrm{~A}$, and ${ }^{2,4} \mathrm{~A}$ product ions. Two cross-ring fragments within the branching mannose residue were observed, including ${ }^{1,5} \mathrm{~A}_{5}$ and ${ }^{4,5} \mathrm{X}_{2}$. The latter ion provides information regarding the linkage position of the $\alpha$-branch. Similar to other EDD spectra, $\mathrm{Y}-16 \mathrm{Da}$ product ions are also observed. Also detected was an ion due to loss of a fucose residue, $\mathrm{Y}_{1 \gamma}$, which was not observed following CAD or IRMPD. In negative-ion mode, it has been observed that fucose tends not to be lost following CAD [23], a trend that is not observed in EDD. EDD of this branched glycan demonstrates that EDD fragmentation efficiency does not seem to be affected by oligosaccharide branching. We have shown that ECD of larger, branched oligosaccharides requires ion activation (presumably due to secondary structure) to fragment efficiently [31]. However, electron energies used for EDD (20-30 eV in the current experiments) are much higher than those typically used for ECD $(<1 \mathrm{eV})$. These higher electron energies likely contribute to disruption of any intramolecular non-covalent interactions.

\section{Conclusions}

Our results demonstrate that EDD of neutral and sialylated oligosaccharides provides structural information that is complementary to that obtained following IRMPD and CAD. One potential issue with this approach is that, for neutral and singly sialylated oligosaccharides, doubly charged anions (which are required for EDD) are sometimes more difficult to obtain than are singly charged anions. However, for both the neutral glycan (NA2) and the singly sialylated glycan (A1F) examined here, doubly deprotonated species were more easily produced in negative-ion mode ESI compared to the corresponding singly deprotonated species. These results indicate that EDD is a potentially valuable tool for the characterization of biologically relevant N-linked glycans, even if they are not highly acidic. Cross-ring cleavages observed following IRMPD and CAD of doubly and singly deprotonated oligosaccharides were typically either ${ }^{0,2} \mathrm{~A}$ or ${ }^{2,4} \mathrm{~A}$ type cleavages. These product ion types can also be observed following IRMPD and low-energy CAD in positive-ion mode MS/MS, however, cross-ring fragments are generally more prevalent for metal adducted oligosaccharides compared to protonated species. Following EDD, several additional types of cross-ring cleavages were observed, such as ${ }^{3,5} \mathrm{~A},{ }^{1,5} \mathrm{~A},{ }^{1,5} \mathrm{X}$, and ${ }^{3,5} \mathrm{X}$ type ions. These product ion types are usually not produced from either positive- or negative-ion mode IRMPD or low-energy CAD. In most cases, cross-ring fragmentation in EDD was more extensive than in CAD or IRMPD. A comparison of the frag- mentation patterns of branched and linear oligosaccharides demonstrates that branching does not seem to affect EDD fragmentation. Throughout these experiments, several unique product ions were observed. These include $\mathrm{C}$ $-2 \mathrm{H}, \mathrm{Y}-16 \mathrm{Da}$, and $\mathrm{Y}-2 \mathrm{H}$ product ions. These ion types have all been observed following heCAD, but only $\mathrm{C}-2 \mathrm{H}$ ions have been noted following EDD of GAGs.

\section{Acknowledgments}

This work was supported by the Searle Scholars Program, an Analytical Chemistry award from Eli Lilly \& Company, a Dow Corning Assistant Professorship, a Rackham Predoctoral Fellowship, and the University of Michigan.

\section{References}

1. Varki, A. Biological Roles of Oligosaccharides: All of the Theories Are Correct. Glycobiology 1993, 3, 97-130.

2. Dwek, R. A. Glycobiology: Toward Understanding the Function of Sugars. Chem. Rev. 1996, 96, 683-720.

3. Parodi, A. J. Protein Glycosylation and Its Role in Protein Folding. Annu. Rev. Biochem. 2000, 69, 60-93.

4. Rudd, P. M.; Elliott, T.; Cresswell, P.; Wilson, I. A.; Dwek, R. A. Glycosylation and the Immune System. Science 2001, 291, 2370-2376.

5. Harvey, D. J. Matrix-assisted Laser Desorption/Ionization Mass Spectrometry of Carbohydrates. Mass Spectrom. Rev. 1999, 18, 349-451.

6. Zaia, J. Mass Spectrometry of Oligosaccharides. Mass Spectrom. Rev. 2004, 23, 161-227

7. Park, Y.; Lebrilla, C. B. Application of Fourier Transform Ion Cyclotron Resonance Mass Spectrometry to Oligosaccharides. Mass Spectrom. Rev. 2005, 24, 232-264.

8. Reinhold, V. N.; Reinhold, B. B.; Costello, C. E. Carbohydrate Molecular-weight Profiling, Sequence, Linkage, and Branching Data-ES-MS and CID. Anal. Chem. 1995, 67, 1772-1784.

9. Weiskopf, A. S.; Vouros, P.; Harvey, D. J. Characterization of Oligosaccharide Composition and Structure by Quadrupole Ion Trap Mass Spectrometry. Rapid Commun. Mass Spectrom. 1997, 11, 1493-1504.

10. Viseux, N.; de Hoffmann, E.; Domon, B. Structural Analysis of Permethylated Oligosaccharides by Electrospray Tandem Mass Spectrometry. Anal. Chem. 1997, 69, 3139-3198.

11. Zhou, Z.; Ogden, S.; Leary, J. A. Linkage Position Determination in Oligosaccharides: MS/MS Study of Lithium-cationized Carbohydrates. J. Org. Chem. 1990, 55, 5446-5448.

12. Orlando, R.; Bush, C. A.; Fenselau, C. Structural Analysis of Oligosaccharides by Tandem Mass Spectrometry: Collisional Activation of Sodium Adduct Ions. Biomed. Environ. Mass Spectrom. 1990, 19, 747-754.

13. Fura, A.; Leary, J. A. Differentation of $\mathrm{Ca}^{2+}-$ and $\mathrm{Mg}^{2+}-$ Coordinated Branched Trisaccharide Isomers: An Electrospray Ionization and Tandem Mass Spectrometry Study. Anal. Chem. 1993, 65, 2805-2811.

14. Cancilla, M. T.; Penn, S. G.; Carroll, J. A.; Lebrilla, C. B. Coordination of Alkali Metals to Oligosaccharides Dictates Fragmentation Behavior in Matrix Assisted Laser Desorption Ionization Fourier Transform Mass Spectrometry. J. Am. Chem. Soc. 1996, 118, 6736-6745.

15. Domon, B.; Costello, C. E. A Systematic Nomenclature for Carbohydrate Fragmentations in FAB-MS/MS Spectra of Glycoconjugates. Glycoconjugate J. 1988, 5, 397-409.

16. Dallinga, J.; Heerma, W. Reaction Mechanism and Fragment ion Structure Determination of Deprotonated Small Oligosaccharides, Studied by Negative Ion Fast Atom Bombardment (Tandem) Mass Spectrometry. Biol. Mass Spectrom. 1991, 20, 215-231.

17. Li, D. T.; Her, G. R. Linkage Analysis of Chromophore-labeled Disaccharides and Linear Oligosaccharides by Negative Ion Fast atom Bombardment Ionization and Collisional-induced Dissociation with B/E Scanning. Anal. Biochem. 1993, 211, 250-257.

18. Carroll, J. A.; Ngoka, L. C.; Beggs, C. G.; Lebrilla, C. B. Liquid Secondary Ion Mass Spectrometry/Fourier Transform Mass Spectrometry of Oligosaccharide Anions. Anal. Chem. 1993, 65, 1582-1587.

19. Chai, W.; Piskarev, V.; Lawson, A. M. Negative-ion Electrospray Mass Spectrometry of Neutral Underivatized Oligosaccharides. Anal. Chem. 2001, 73, 651-657.

20. Pfenninger, A.; Karas, M.; Finke, B.; Stahl, B. Structural Analysis of Underivatized Neutral Human Milk Oligosaccharides in the Negative Ion Mode by Nano-electrospray MSn (Part 1: Methodology). J. Am. Soc. Mass Spectrom. 2002, 13, 1331-1340.

21. Pfenninger, A.; Karas, M.; Finke, B.; Stahl, B. Structural Analysis of Underivatized Neutral Human Milk Oligosaccharides in the Negative Ion Mode by Nano-electrospray MSn (Part 2: Application to Isomeric Mixtures). J. Am. Soc. Mass Spectrom. 2002, 13, 1341-1348.

22. Chai, W.; Lawson, A. M.; Piskarev, V. Branching Pattern and Sequence Analysis of Underivatized Oligosaccharides by Combined MS/MS of 
Singly and Doubly Charged Molecular Ions in Negative-ion Electrospray Mass Spectrometry. J. Am. Soc. Mass Spectrom. 2002, 13, 670-679.

23. Harvey, D. J. Fragmentation of Negative Ions from Carbohydrates: Part 1. Use of Nitrate and Other Anionic Adducts for the Production of Negative Ion Electrospray Spectra from N-linked Carbohydrates. J. Am. Soc. Mass Spectrom. 2005, 16, 622-630.

24. Seymour, J. L.; Costello, C. E.; Zaia, J. The Influence of Sialylation on Glycan Negative ion Dissociation and Energetics. J. Am. Soc. Mass Spectrom. 2006, 17, 844-854.

25. Lemoine, J.; Strecker, G.; Leroy, Y.; Fournet, B.; Ricart, G. Collisionalactivation Tandem Mass-Spectrometry of Sodium Adduct Ions of Methylated Oligosaccharides-Sequence-Analysis and Discrimination between alpha-NeuAc- $(2 \rightarrow 3)$ and alpha-NeuAc- $(2 \rightarrow 6)$ Linkages. Carbohydr. Res. 1991, 221, 209-217.

26. Harvey, D. J.; Naven, T. J. P.; Kuster, B.; Bateman, R. H.; Green, M. R.; Critchley, G. Comparison of Fragmentation Modes for the Structural Determination of Complex Oligosaccharides Ionized by Matrix-assisted Laser Desorption/Ionization Mass Spectrometry. Rapid Commun. Mass Spectrom. 1995, 9, 1556-1561.

27. Mechref, Y.; Novotny, M. V. Structural Characterization of Oligosaccharides Using MALDI-TOF/TOF Tandem Mass Spectrometry. Anal. Chem. 2003, 75, 4895-4903.

28. Shi, S. D.-H.; Hendrickson, C. L.; Marshall, A. G.; Seigel, M. M.; Kong, F.; Carter, G. T. Structural Validation of Saccharomicins by High Resolution and High Mass Accuracy FTICR MS and IRMPD Mass Spectrometry. J. Am. Soc. Mass Spectrom. 1999, 10, 1285-1290.

29. Xie, Y. M.; Lebrilla, C. B. Infrared Multiphoton Dissociation of Alkali Metal-coordinated Oligosaccharides. Anal. Chem. 2003, 75, 1590-1598.

30. Budnik, B. A.; Haselmann, K. F.; Elkin, Y. N.; Gorbach, V. I.; Zubarev, R. A. Applications of Electron-Ion Dissociation Reactions for Analysis of Polycationic Chitooligosaccharides in Fourier Transform Mass Spectrometry. Anal. Chem. 2003, 75, 5994-6001.

31. Adamson, J. T.; Håkansson, K. Electron Capture Dissociation of Oligosaccharides Ionized with Alkali, Alkaline Earth, and Transition Metals. Anal. Chem. 2007, 79, 2901-2910.

32. Wolff, J. J.; Amster, I. J.; Chi, L.; Linhardt, R. J. Electron Detachment Dissociation of Glycosaminoglycan Tetrasaccharides. J. Am. Soc. Mass Spectrom. 2006, 18, 234-244.

33. Wolff, J. J.; Chi, L.; Linhardt, R. J.; Amster, I. J. Distinguishing Glucuronic from Iduronic Acid in Glycosaminoglycan Tetrasaccharides by Using Electron Detachment Dissociation. Anal. Chem. 2007, 79, 20152022.

34. Devakumar, A.; Thompson, M. S.; Reilly, J. P. Fragmentation of Oligosaccharide Ions with $157 \mathrm{~nm}$ Vacuum Ultraviolet Light. Rapid Commun. Mass Spectrom. 2005, 19, 2313-2320.

35. Cooper, H. J.; Håkansson, K.; Marshall, A. G. The Role of Electron Capture Dissociation in Biomolecular Analysis. Mass Spectrom. Rev. 2005, 24, 201-222.

36. Mirgorodskaya, E.; Roepstorff, P.; Zubarev, R. A. Localization of O-Glycosylation Sites in Peptides by Electron Capture Dissociation in a Fourier Transform Mass Spectrometer. Anal. Chem. 1999, 71, 4431-4436.

37. Håkansson, K.; Cooper, H. J.; Emmett, M. R.; Costello, C. E.; Marshall, A. G.; Nilsson, C. L. Electron Capture Dissociation and Infrared Multiphoton Dissociation MS/MS of an N-Glycosylated Tryptic Peptide Yield Complementary Sequence Information. Anal. Chem. 2001, 73, $4530-4536$

38. Kjeldsen, F.; Haselmann, K. F.; Budnik, B. A.; Sorensen, E. S.; Zubarev, R. A. Complete Characterization of Posttranslational Modification Sites in the Bovine Milk Protein PP3 by Tandem Mass Spectrometry with Electron Capture Dissociation as the Last Stage. Anal. Chem. 2003, 75, 2355-2361.

39. Håkansson, K.; Chalmers, M. J.; Quinn, J. P.; McFarland, M. A.; Hendrickson, C. L.; Marshall, A. G. Combined Electron Capture and Infrared Multiphoton Dissociation for Multistage MS/MS in an FT-ICR Mass Spectrometer. Anal. Chem. 2003, 75, 3256-3262.

40. Mormann, M.; Macek, B.; de Peredo, A. G.; Hofsteenge, J.; PeterKatalinic, J. Structural Studies on Protein O-Fucosylation by Electron Capture Dissociation. Int. J. Mass Spectrom. 2004, 234, 11-21.

41. Adamson, J. T.; Håkansson, K. Infrared Multiphoton Dissociation and Electron Capture Dissociation of High-Mannose Type Glycopeptides. J. Proteome Res. 2006, 5, 493-501.

42. Zubarev, R. A.; Kelleher, N. L.; McLafferty, F. W. Electron Capture Dissociation of Multiply Charged Protein Cations. A Nonergodic Process. J. Am. Chem. Soc. 1998, 120, 3265-3266.

43. Zubarev, R. A.; Kruger, N. A.; Fridriksson, E. K.; Lewis, M. A.; Horn, D. M.; Carpenter, B. K.; McLafferty, F. W. Electron Capture Dissociation of Gaseous Multiply-charged Proteins Is Favored at Disulfide Bonds and Other Sites of High Hydrogen Atom Affinity. J. Am. Chem. Soc. 1999, 121, 2857-2862.

44. Zhao, C.; Xie, B.; Cournoyer, J.; Chan, S. Y.; Zaia, J.; Costello, C. $\mathrm{O}^{\prime}$ Connor, P. 55th ASMS Conference on Mass Spectrometry and Allied Topics, Indianapolis, IN, June 3-7, 2007; poster presentation.

45. Budnik, B. A.; Haselmann, K. F.; Zubarev, R. A. Electron Detachment Dissociation of Peptide Di-anions: An Electron-hole Recombination Phenomenon. Chem. Phys. Lett. 2001, 342, 299-302.

46. Kjeldsen, F.; Silivra, O. A.; Ivonin, I. A.; Haselmann, K. F.; Gorshkov, M. Zubarev, R. A C-alpha-C Backbone Fragmentation Dominates in Electron Detachment Dissociation of Gas-phase Polypeptide Polyanions. Chem. Eur. J. 2005, 11, 1803-1812.
47. Kalli, A.; Håkansson, K. Preferential Cleavage of S S and C-S Bonds in Electron Detachment Dissociation and Infrared Multiphoton Dissociation of Disulfide-linked Peptide Anions. Int. J. Mass Spectrom. 2007, 263, 71-81.

48. Yang, J.; Mo, J.; Adamson, J. T.; Håkansson, K. Characterization of Oligonucleotides by Electron Detachment Dissociation Fourier Transform Ion Cyclotron Resonance Mass Spectrometry. Anal. Chem. 2005, 77, 1876-1882.

49. Mo, J.; Håkansson, K. Characterization of Nucleic Acid Higher Order Structure by High-resolution Tandem Mass Spectrometry. Anal. Bioanal. Chem. 2006, 386, 675-681.

50. McFarland, M. A.; Marshall, A. G.; Hendrickson, C. L.; Nilsson, C. L. Fredman, P.; Mansson, J. E. Structural Characterization of the GM1 Ganglioside by Infrared Multiphoton Dissociation/Electron Capture Dissociation, and Electron Detachment Dissociation Electrospray Ionization FT-ICR MS/MS. J. Am. Soc. Mass Spectrom. 2005, 16, 752-762.

51. Caravatti, P.; Allemann, M. The Infinity Cell-A New Trapped Ion cell with Radiofrequency Covered Trapping Electrodes for Fourier Transform Ion Cyclotron Resonance Mass Spectrometry. Org. Mass Spectrom. 1991, 26, 514-518.

52. Heck, A. J. R.; Derrick, P. J. Ultrahigh Mass Accuracy in Isotope Selective Collision-induced Dissociation Using Correlated Sweep Excitation and Sustained Off-resonance Irradiation: A Fourier Transform Mass Spectrometry Case Study on the $[\mathrm{M}+2 \mathrm{H}]^{2+}$ Ion of Bradykinin. Anal. Chem. 1997, 69, 3603-3607.

53. Tsybin, Y. O.; Witt, M.; Baykut, G.; Kjeldsen, F.; Håkansson, P. Combined Infrared Multiphoton Dissociation and Electron Capture Dissociation with a Hollow Electron Beam in Fourier Transform Ion Cyclotron Resonance Mass Spectrometry. Rapid Commun. Mass Spectrom. 2003, 17, 1759-1768.

54. Senko, M. W.; Canterbury, J. D.; Guan, S.; Marshall, A. G. A Highperformance Modular Data System for FT-ICR Mass Spectrometry. Rapid Commun. Mass Spectrom. 1996, 10, 1839-1844.

55. Lohmann, K. K.; von der Lieth, C. W. GlycoFragment and GlycoSearchMS: Web Tools to Support the Interpretation of Mass Spectra of Complex Carbohydrates. Nucleic Acids Res. 2004, 32, 261-266.

56. Zhang, J. H.; Schubothe, K.; Li, B. S.; Russell, S.; Lebrilla, C. B. Infrared Multiphoton Dissociation of O-linked Mucin-type Oligosaccharides. Anal. Chem. 2005, 77, 208-214.

57. Harvey, D. J.; Bateman, R. H.; Green, B. N. High-energy Collisioninduced Fragmentation of Complex Oligosaccharides Ionized by $\mathrm{Ma}-$ trix-assisted Laser Desorption/Ionization Mass Spectrometry. I. Mass Spectrom. 1997, 32, 167-187.

58. Kovacik, V.; Hirsch, J.; Kovac, P.; Heerma, W.; Thomas-Oates, J.; Haverkamp, J. Oligosaccharide Characterization Using Collision-induced Dissociation Fast Atom Bombardment Mass Spectrometry: Evidence for Internal Monosaccharide Residue Loss. J. Mass Spectrom. 1995, 30, 949-958.

59. O'Connor, P. B.; Lin, C.; Cournoyer, J. J.; Pittman, J. L.; Belyayev, M.; Budnik, B. A. Long-lived Electron Capture Dissociation Product Ions Experience Radical Migration via Hydrogen Abstraction. J. Am. Soc. Mass Spectrom. 2006, 17, 576-585.

60. Savitski, M. M.; Kjeldsen, F.; Nielsen, M. L.; Zubarev, R. A Hydrogen Rearrangement to and from Radical z Fragments in Electron Capture Dissociation of Peptides. J. Am. Soc. Mass Spectrom. 2006, 18, 113-120.

61. Küster, B.; Naven, T. J. P.; Harvey, D. J. Effect of the Reducing-terminal Substituents on the High Energy Collision-induced Dissociation Matrixassisted Laser Desorption/Ionization Mass Spectra of Oligosaccharides. Rapid Commun. Mass Spectrom. 1996, 10, 1645-1651.

62. Stephens, E.; Maslen, S. L.; Green, L. G.; Williams, D. H. Fragmentation Characteristics of Neutral-N-linked Glycans Using a MALDI-TOF/TOF Tandem Mass Spectrometer. Anal. Chem. 2004, 76, 2343-2354.

63. Lewandrowski, U.; Resemann, A.; Sickmann, A. Laser-induced Dissociation/High-energy Collision-induced Dissociation Fragmentation Using MALDI-TOF/TOF-MS Instrumentation for the Analysis of Neutral and Acidic Oligosaccharides. Anal. Chem. 2005, 77, 3274-3283.

64. Yu, S.; Wu, S.; Khoo, K. Distinctive Characteristics of MALDI-Q/TOF and TOF/TOF Tandem Mass Spectrometry for Sequencing of Permethylated Complex Type N-Glycans. Glyconjugate J. 2006, 23, 355-369.

65. Harvey, D. J. Fragmentation of Negative Ions from Carbohydrates: Part 3. Fragmentation of Hybrid and Complex N-linked Glycans. J. Am. Soc. Mass Spectrom. 2005, 16, 647-659.

66. Hardy, M. R.; Townsend, R. R. High-pH Anion Exchange Chromatography of Glycoprotein-derived Carbohydrates. Methods Enzymol. 1994, 230, 208-225.

67. Neuberger, A.; Wilson, B. M. The Separation of Glycosides on a Strongly Basic Ion-Exchange Resin: An Interpretation in Terms of Acidity. Carbohydr. Res. 1971, 17, 89-95.

68. Ernst, B.; Müller, R. T.; Richter, W. J. False Sugar Sequence Ions in Electrospray Tandem Mass Spectrometry of Underivatized SialylLewis-Type Oligosaccharides. Int. J. Mass. Spectrom. Ion Processes 1997, 160, 283-290.

69. Brüll, L. P.; Heerma, W.; Thomas-Oates, J.; Haverkamp, J.; Kovácik, V.; Kovác, P. Loss of Internal $1 \rightarrow 6$ Substituted Monosaccharide Residues from Underivatized and Per-O-methylated Trisaccharides. J. Am. Soc Mass Spectrom. 1997, 8, 43-49.

70. Harvey, D. J.; Mattu, T. S.; Wormald, M. R.; Royle, L.; Dwek, R. A. Rudd, P. M. "Internal Residue Loss"; Rearrangements Occurring during the Fragmentation of Carbohydrates Derivatized at the Reducing Terminus. Anal. Chem. 2002, 74, 734-740. 